\title{
TATALAKSANA GAGAL NAFAS AKUT AKIBAT EDEM PARU AKUT PADA PASIEN DENGAN HIPERTENSI
}

\author{
${ }^{1)}$ Matdhika Sakti, ${ }^{2)}$ Ferianto, ${ }^{3)}$ Dea Vilia Siswoyo, ${ }^{4)}$ Fifi Candita, ${ }^{5)}$ Ria Finola Ifani \\ ${ }^{1,2)}$ Bagian Anestesiologi dan Reanimasi, RSUD Kota Dumai \\ ${ }^{1,2)}$ Jl. Tanjung Jati No.4, Dumai Timur, Kota Dumai, Riau, 28812 \\ ${ }^{3,4,5)}$ Fakultas Kedokteran, Universitas Abdurrab \\ ${ }^{3,4,5)}$ Jl. Riau Ujung No. 73 Pekanbaru - Riau - Indonesia \\ E-mail : ${ }^{1)}$ matdhika.sakti@univrab.ac.id,${ }^{2)}$ ferianto@student.univrab.ac.id,${ }^{3)}$ dea.vilia.s16@student.univrab.ac.id \\ ,${ }^{4)}$ fifi.candita@student.univrab.ac.id,${ }^{5)}$ ria.finola.i16@student.univrab.ac.id
}

\section{Kata Kunci:}

respiratory

cardiogenic pulmonary

oedem, saturasi O2,

ventilator, kesadaran

\begin{abstract}
ABSTRAK
Gagal nafas merupakan kondisi kegagalan fungsi sistem respirasi dalam pertukaran gas di mana $\mathrm{PaO} 2<60 \mathrm{mmHg}$ dan/ $\mathrm{PaCO} 2>50 \mathrm{mmHg}$. Telah dilakukan tindakan kepada seorang pasien laki-laki berusia tujuh puluh satu tahun dengan berat badan $70 \mathrm{~kg}$ yang di bawa ke IGD RSUD Kota Dumai dengan keadaan penurunan kesadaran. Dari alloanamnesa terhadap keluarga pasien, diketahui sebelumnya pasien mengeluhkan sesak nafas yang muncul tiba-tiba. Pasien memiliki riwayat penyakit jantung yang diketahui sejak 6 bulan terakhir dan hipertensi tidak terkontrol. Pasien didiagnosis dengan respiratory failure type 1 et causa cardiogenic pulmonary oedem. Saat di ICU, saturasi $\mathrm{O}_{2}$ pasien turun menjadi $77 \%$ sehingga pasien diberikan bagging untuk bantuan nafas kemudian saturasi $\mathrm{O}_{2}$ naik menjadi $90 \%$, kemudian pasien mengalami apneu, asistol dan arteri karotis tidak teraba sehingga dilakukan RJP kompresi: ventilasi 30:2 dengan total 15 siklus dan pasien mengalami ROSC. Pasien kemudian dipasang intubasi dan dibantu ventilator, saturasi $\mathrm{O}_{2}$ menjadi $99 \%$. Sebelumnya pasien diberikan midazolam $15 \mathrm{mg}$ di dalam 50ml $\mathrm{NaCl}$ melalui syringe pump dan fentanyl 2 ampul dalam 50cc $\mathrm{NaCl} 50 \mathrm{ml}$ melalui syringe pump. Kemudian, pola nafas tidak efektif dan keadaan umum memburuk, ventilator diubah menjadi mode PCAC kemudian pernafasan kembali adekuat dan hemodinamik pasien stabil. Kemudian pada pasien dilakukan weaning ventilator.
\end{abstract}

\begin{abstract}
Respiratory failure is a condition of respiratory system failure in gas exchange where $\mathrm{PaO} 2<60 \mathrm{mmHg}$ and $/ \mathrm{PaCO} 2>50 \mathrm{mmHg}$. An action was taken on a seventy-one year old male patient with a weight of $70 \mathrm{~kg}$ who was brought to the ER at the Dumai City Hospital with a decreased state of consciousness. From the alloanamnesis of the patient's family, it was known that the patient previously complained of shortness of breath that appeared suddenly. The patient had a known history of heart disease since the last 6 months and uncontrolled hypertension. The patient was diagnosed with respiratory failure type 1 and causes cardiogenic pulmonary edema. While in the ICU, the patient's O2 saturation fell to $77 \%$ so that the patient was given bagging for breath support then the O2 saturation rose to $90 \%$, then the patient experienced apnea, asystole and the carotid artery was not palpable so compression CPR was performed: ventilation 30:2 for a total of 15 cycles. and the patient had ROSC. The patient was then intubated and assisted by a ventilator, the O2 saturation being 99\%. Previously, the patient was given midazolam $15 \mathrm{mg}$ in $50 \mathrm{ml} \mathrm{NaCl}$ via a syringe pump and 2 ampoules of fentanyl in $50 \mathrm{cc} \mathrm{NaCl} 50 \mathrm{ml}$ via a syringe pump. Then, the breathing pattern is ineffective and the general condition worsens, the ventilator is changed to PCAC mode then breathing is adequate again and the patient's hemodynamics is stable. Then the patient was given a weaning ventilator.
\end{abstract}

\section{PENDAHULUAN}

Gagal nafas adalah suatu kondisi dimana sistem respirasi gagal melakukan fungsi pertukaran gas yaitu pemasukan oksigen dan pengeluaran karbondioksida. Secara menyeluruh, penyebaran frekuensi gagal napas tidak diketahui karena gagal napas merupakan kumpulan gejala dari suatu penyakit dari pada proses penyakit tunggal. Kegagalan pernapasan dapat disebabkan oleh kelainan pada paru atau di luar paru yang meliputi: 1 . depresi sistem saraf pusat 
pada kasus overdosis narkotika dan obat penenang, 2. gangguan sistem saraf perifer seperti kelemahan otot pernapasan dan dinding dada pada kasus sindrom GuillianBarre dan miastenia gravis, 3. obstruksi saluran napas atas dan bawah karena berbagai penyebab seperti pada kasus eksaserbasi penyakit paru obstruktif kronik dan asma bronkial akut berat, 4. kelainan pada alveolus yang mengakibatkan gagal napas tipe 1 (hipoksemik) seperti pada kasus edema paru dan pneumonia berat [1].

Gejala dan tanda gagal nafas menggambarkan adanya hipoksemia atau hiperkapnia, atau keduanya, disertai gejala dari penyakit yang mendasarinya. Sesak merupakan gejala yang sering muncul sedangkan penurunan status mental adalah gejala akibat hipoksemia maupun hiperkapnia [2]. Menurut Shebl, Eman et al $^{1}$ terdapat manifestasi klinis gagal nafas yang dapat ditemukan pada pemeriksaan fisik seperti: gejala dan tanda hipoksemia diantaranya dispnea, mudah tersinggung, kebingungan, mengantuk, takikardia, aritmia, takipnea dan sianosis ataupun gejala dan tanda hiperkapnia yaitu sakit kepala, perubahan perilaku, koma, asterixis, papilloedema dan ekstremitas hangat.

\section{LAPORAN KASUS}

Seorang pasien laki-laki berusia tujuh puluh satu tahun dengan berat badan $70 \mathrm{~kg}$ di bawa ke IGD RSUD Kota Dumai dengan keadaan penurunan kesadaran. Dari alloanamnesis keluarga pasien, diketahui pasien mengeluhkan sesak nafas yang muncul tiba-tiba dan semakin memberat. Pasien sudah sering merasakan sesak sejak 1 bulan terakhir bahkan sesak dialami pada saat beraktivitas ringan. Pasien memiliki riwayat penyakit jantung yang diketahui sejak 6 bulan terakhir dan hipertensi tidak terkontrol. Saat dilakukan pemeriksaan fisik, kesadaran pasien menurun GCS 11 (somnolen), frekuensi nafas 32x/menit (takipnea), frekuensi nadi 142x/menit (takikardi), tekanan darah $210 / 110 \mathrm{mmHg}$, $\mathrm{SpO}_{2} 44 \%$ dan akral dingin. Dari hasil anamnesis, pemeriksaan fisik dan pemeriksaan penunjang, pasien didiagnosis dengan respiratory failure type 1 et causa cardiogenic pulmonary oedem.

\section{Metode Tindakan}

Saat di IGD, pasien diberikan terapi berupa oksigen dengan NRM 15L, IVFD $\mathrm{NaCl}$ 0,9\%, lansoprazol, furosemid, morphin, nitrogliserin. Pasien mengalami perbaikan dimana saturasi $\mathrm{O}_{2}$ dari $44 \%$ menjadi $90 \%$, frekuensi nadi $142 \mathrm{x} / \mathrm{menit}$ menjadi 140x/menit, nafas dari $32 \mathrm{x} /$ menit menjadi 30x/menit serta tekanan darah $210 / 110 \mathrm{mmHg}$ menjadi 140/80mmHg. Pasien kemudian dikonsulkan ke Unit Perawatan Intensif (ICU) untuk tatalaksana lanjutan. Pasien kemudian dirawat di ICU selama 6 hari hingga mengalami perbaikan dan dipindahkan ke ruang observasi.

Saat di ICU, tanda-tanda vital pasien dipantau secara ketat. Pada tanggal 17 maret 2021 pukul 04.00, saturasi $\mathrm{O}_{2}$ pasien turun menjadi $77 \%$ sehingga pasien diberikan bagging untuk bantuan nafas kemudian saturasi $\mathrm{O}_{2}$ naik menjadi $90 \%$, lalu pada pukul 05.00 saturasi turun menjadi $87 \%$. Pada pukul 06.00 saturasi $\mathrm{O}_{2}$ semakin menurun menjadi $82 \%$ di mana pasien telah diberikan $\mathrm{O}_{2}$ melalui NRM 15L/menit sebelumnya dan tidak ada perbaikan sehingga pasien direncanakan untuk dilakukan pemasangan intubasi. Tetapi pada pukul 06.00 intubasi tidak terpasang akibat rahang pasien masih kaku. Pukul 06.30 pasien mengalami apneu, asistol dan arteri karotis tidak teraba sehingga dilakukan RJP kompresi: ventilasi 30:2 dengan total 15 siklus dan pasien mengalami ROSC. Pukul 07.00 pada pasien terpasang intubasi dan dibantu ventilator, saturasi $\mathrm{O}_{2}$ menjadi $99 \%$.

Pada tanggal 17 maret 2021 pukul 07.20, pasien terpasang intubasi dengan ventilator mode controlled volume, volume tidal 460, RR 16x/menit, PEEP 8 dan saturasi $0_{2} 100 \%$. Sebelumnya pasien diberikan midazolam $15 \mathrm{mg}$ di dalam $50 \mathrm{ml} \mathrm{NaCl}$ melalui syringe pump dan fentanyl 2 ampul dalam $50 \mathrm{cc} \mathrm{NaCl}$ $50 \mathrm{ml}$ melalui syringe pump. Pada tanggal 18 
maret 2021 pukul 14.00 pola nafas tidak efektif dan keadaan umum memburuk, ventilator diubah menjadi mode PCAC kemudian pernafasan kembali adekuat dan hemodinamik pasien stabil. Pada tanggal 19 maret 2021 pukul 16.00 pola pasien menjadi tidak efektif kembali dan ventilator diubah menjadi mode SIMV kemudian pola nafas kembali efektif. Pada tanggal 20 maret 2021 pukul 10.00 pada pasien dilakukan weaning ventilator. Fungsi respirasi dan hemodinamik pasien sudah stabil di mana RR $14 \mathrm{x} /$ menit, $\mathrm{SpO} 2$ 99\%, HR $85 \mathrm{x} /$ menit, suhu $36,5^{\circ} \mathrm{C}$ dan kesadaran komposmentis. Setelah dilakukan weaning, pada pukul 16.00 fungsi pernafasan dan hemodinamik pasien stabil (RR 14x/menit, HR 85x/menit, $\mathrm{SpO}_{2} 99 \%$ ).

\section{PEMBAHASAN}

Pasien tersebut dicurigai mengalami gagal nafas. Gagal nafas diklasifikasikan menjadi gagal nafas tipe 1, gagal nafas tipe 2 dan gagal nafas tipe 3 menurut kelainan gas darah. Pada gagal nafas tipe 1 (hipoksemik), tekanan parsial oksigen arteri $(\mathrm{PaO} 2)<60 \mathrm{mmHg}$, dan tekanan parsial karbon dioksida arteri (PaCO2) bisa normal atau rendah. Tipe ini merupakan tipe yang umum ditemukan, dan berkaitan dengan hampir semua kelainan paru akut yang berkaitan dengan hipoventilasi, ketidakseimbangan ventilasi-perfusi (V/P mismatch), maupun ketidakseimbangan suplai oksigen dengan kebutuhan oksigen jaringan (DO2/VO2 mismatch). Etiologi dari gagal napas tipe 1 yaitu edema paru, pneumonia, pneumo-toraks, emboli paru, ARDS (Acute Respiratory Distress Syndrome).

Pada gagal nafas tipe 2 (hiperkapnik), $\mathrm{PaCO} 2>50 \mathrm{mmHg}$, dan $\mathrm{PaO} 2$ mungkin normal atau rendah. Etiologi tersering dari gagal napas tipe 2 meliputi overdosis obat, penyakit neuromuskular, kelainan dinding dada, serta kelainan saluran napas berat (Asma, Penyakit Paru Obstruktif KronikPPOK). Gagal nafas tipe 3 adalah gabungan antara kegagalan oksigenasi dan ventilasi ditandai dengan hipoksemia dan hiperkapnia penurunan $\mathrm{PaO} 2$ dan peningkatan $\mathrm{PaCO} 2$ $[1,3]$. Kriteria kadar gas darah arteri untuk gagal respirasi tidak mutlak bisa ditentukan dengan mengetahui $\mathrm{PO} 2$ kurang dari $60 \mathrm{mmHg}$ dan $\mathrm{PCO} 2$ diatas $50 \mathrm{mmHg}$.

Pasien memiliki riwayat penyakit jantung yang diketahui sejak 6 bulan terakhir dan riwayat hipertensi tidak terkontrol. Dari hasil pemeriksaan rontgen thoraks ditemukan adanya cardiomegali dan edema paru bilateral serta pemeriksaan enzim jantung menunjukkan adanya peningkatan troponin I $(0,54 \mathrm{mg} / \mathrm{ml})$ sehingga kemungkinan penyebab gagal nafas adalah akibat edem paru kardiogenik.

Edema paru adalah akumulasi cairan yang berlebihan di dinding alveolar dan ruang alveolar paru-paru. Edema paru dibedakan menjadi edem paru kardiogenik (mekanisme starling terganggu yang melibatkan pembuluh darah paru dan interstitium) dan nonkardiogenik (cedera langsung/kerusakan parenkim paru/ pembuluh darah). Semua faktor yang berkontribusi terhadap peningkatan tekanan di sisi kiri dan pengumpulan darah di sisi kiri jantung dapat menyebabkan edema paru kardiogenik. Penyebab edem paru kardiogenik yaitu penyakit arteri koroner dengan kegagalan ventrikel kiri (infark miokard), gagal jantung kongestif, kardiomiopati, penyakit katup jantung di sisi kiri jantung (stenosis dan regurgitasi), aritmia jantung, shunt kanan ke kiri. Akibat dari semua kondisi ini akan terjadi peningkatan tekanan di sisi kiri jantung: peningkatan tekanan vena pulmonal $\rightarrow$ peningkatan tekanan hidrostatik kapiler di paru $\rightarrow$ cairan di ruang interstisial masuk ke dalam alveoli $\rightarrow$ edema paru [4].

Perkembangan akumulasi cairan pada edem paru kardiogenik dapat diidentifikasi sebagai tiga tahap fisiologis yang berbeda yaitu [5]:

\section{a. Tahap 1}

Pada tahap 1, peningkatan tekanan atrium kiri menyebabkan distensi dan pembukaan pembuluh darah paru kecil. Pada tahap ini, pertukaran gas darah tidak memburuk, atau bahkan mungkin sedikit meningkat.

b. Tahap 2

Pada tahap 2, cairan dan koloid bergeser ke interstitium paru dari kapiler paru, tetapi peningkatan awal aliran limfatik 
secara efisien menghilangkan cairan. Filtrasi cairan dan zat terlarut yang berkelanjutan dapat mengganggu kapasitas drainase dari limfatik. Dalam kasus ini, cairan awalnya terkumpul di kompartemen interstisial yang relatif sesuai, yang umumnya merupakan jaringan perivaskular pembuluh darah besar, terutama di zona dependen.

Akumulasi cairan di interstitium dapat mengganggu saluran udara kecil, yang menyebabkan hipoksemia ringan. Hipoksemia pada tahap ini jarang cukup untuk merangsang takipnea. Takipnea pada tahap ini terutama merupakan hasil dari stimulasi reseptor kapiler juxtapulmonary (tipe J), yang merupakan ujung saraf nonmyelinated yang terletak di dekat alveoli. Reseptor tipe-J terlibat dalam refleks yang memodulasi pernapasan dan detak jantung.

c. Tahap 3

Pada tahap 3, karena filtrasi cairan terus meningkat dan terjadi akumulasi pengisian ruang interstisial yang relatif tidak sesuai. Ruang interstisial dapat berisi cairan hingga $500 \mathrm{~mL}$. Dengan akumulasi lebih lanjut, cairan melintasi epitel alveolar ke alveoli, menyebabkan kongesti di alveolar. Pada tahap ini, pertukaran gas terlihat, kapasitas vital dan volume pernafasan lainnya berkurang secara substansial, dan hipoksemia menjadi lebih parah. Gagal nafas merupakan komplikasi paling umum dari edem paru kardiogenik.

Prinsip tatalaksana gagal nafas yaitu:

a. Atasi Hipoksemia

Terapi Oksigen

Pada keadaan $\mathrm{PaO} 2$ turun secara akut, perlu tindakan secepatnya untuk menaikkan $\mathrm{PaO} 2$ sampai normal. Berlainan sekali dengan gagal nafas dari penyakit kronik yang menjadi akut kembali dan pasien sudah terbiasa dengan keadaan hiperkarbia sehingga pusat pernafasan tidak terangsang oleh hipercarbia drive melainkan terhadap hypoxemia drive. Akibat kenaikan $\mathrm{PaO} 2$ yang terlalu cepat, pasien dapat menjadi apnoe.

Pemberian oksigen harus dipertimbangkan apakah pasien benar-benar membutuhkan oksigen. Indikasi untuk pemberian oksigen harus jelas. Oksigen yang diberikan harus diatur dalam jumlah yang tepat, dan harus dievaluasi agar mendapat manfaat terapi dan menghindari toksisitas.

Terapi oksigen jangka pendek merupakan terapi yang dibutuhkan pada pasien dengan keadaan hipoksemia akut. Oksigen harus segera diberikan dengan adekuat karena jika tidak diberikan akan menimbulkan cacat tetap dan kematian.

Pada kondisi ini oksigen harus diberikan dengan $\mathrm{FiO} 2$ 60-100\% dalam waktu pendek dan terapi yang spesifik diberikan. Selanjutnya oksigen diberikan dengan dosis yang dapat mengatasi hipoksemia dan meminimalisasi efek samping.

Cara pemberian oksigen secara umum ada 2 macam yaitu sistem arus rendah dan sistem arus tinggi. Kateter nasal kanul merupakan alat dengan sistem arus rendah yang digunakan secara luas. Nasal Kanul arus rendah mengalirkan oksigen ke nasofaring dengan aliran 1-6 L/mnt, dengan FiO2 antara 0,24-0,44 (24 \%44\%). Alat oksigen arus tinggi di antaranya ventury mask dan reservoir nebulizer blenders. Sistem arus tinggi ini dapat mengirimkan sampai $40 \mathrm{~L} / \mathrm{mnt}$ oksigen melalui mask, yang umumnya cukup untuk total kebutuhan respirasi. Dua indikasi klinis untuk penggunaan oksigen dengan arus tinggi ini adalah pasien yang memerlukan pengendalian $\mathrm{FiO} 2$ dan pasien hipoksia dengan ventilasi abnormal.

b. Atasi Hiperkapnia: Perbaiki Ventilasi

Jalan napas (Airway)

Jalan napas sangat penting untuk ventilasi, oksigenasi, dan pemberian obat-obat pernapasan. Pada semua pasien gangguan pernapasan harus dipikirkan dan diperiksa adanya obstruksi jalan napas atas. Pertimbangan untuk insersi jalan napas buatan seperti endotracheal tube (ETT) berdasarkan manfaat dan resiko jalan 
napas buatan dibandingkan jalan napas alami.

Resiko jalan napas buatan adalah trauma insersi, kerusakan trakea (erosi), gangguan respon batuk, resiko aspirasi, gangguan fungsi mukosiliar, resiko infeksi, meningkatnya resistensi dan kerja pernapasan. Keuntungan jalan napas buatan adalah dapat melintasi obstruksi jalan napas atas, menjadi rute pemberian oksigen dan obat-obatan, memfasilitasi ventilasi tekanan positif dan PEEP, memfasilitasi penyedotan sekret, dan rute bronkoskopi fibreoptik.

Indikasi intubasi dan ventilasi mekanik adalah sebagai berikut:

Secara Fisiologis:

1. Hipoksemia menetap setelah pemberian oksigen

2. $\mathrm{PaCO} 2>55 \mathrm{mmHg}$ dengan $\mathrm{pH}<7,25$

3. Kapasitas vital $<15 \mathrm{ml} / \mathrm{kgBB}$ dengan penyakit neuromuscular

Secara Klinis:

1. Perubahan status mental dengan gangguan proteksi jalan napas

2. Gangguan respirasi dengan ketidakstabilan hemodinamik

3. Obstruksi jalan napas (pertimbangkan trakeostomi)

4. Sekret yang banyak yang tidak dapat dikeluarkan pasien

c. Penatalaksanaan Kausatif/Spesifik

Sambil dilakukan resusitasi (terapi suportif) diupayakan mencari penyebab gagal nafas. Pengobatan spesifik ditujukan pada etiologinya, sehingga pengobatan untuk masing-masing penyakit akan berlainan. Terapi kausatif untuk edem paru kardiogenik yaitu [5]:

1. Nitrogliserin

Nitrogliserin (NTG) adalah obat yang paling efektif, dapat diprediksi, dan bekerja cepat yang tersedia untuk pengurangan preload. Beberapa penelitian menunjukkan kemanjuran dan keamanan yang lebih besar dan onset kerja yang lebih cepat dengan NTG dibandingkan dengan furosemid atau morfin sulfat. Penggunaan NTG sublingual dikaitkan dengan pengurangan preload dalam 5 menit dan dengan beberapa pengurangan afterload.

IV NTG dapat dimulai dengan $10 \mathrm{mcg}$ / menit dan kemudian ditingkatkan secara cepat hingga lebih dari $100 \mathrm{mcg}$ / menit. Alternatif lain adalah NTG diberikan $3 \mathrm{mg}$ IV bolus setiap 5 menit.

Dosis antianginal NTG 0,4 mg setiap 5 menit memiliki bioekuivalensi infus NTG IV kurang dari $80 \mathrm{mcg} /$ menit. Oleh karena itu, dosis NTG untuk pasien CPE lebih tinggi dari dosis standar antianginal.

Mengingat waktu paruh nitrat yang pendek, dokter harus merasa nyaman dengan dosis tinggi untuk CPE, terutama pada kebanyakan pasien dengan CPE, yang datang dengan keadaan hiperadrenergik dan tekanan darah cukup tinggi. Namun, nitrat tidak boleh digunakan pada pasien hipotensi, dan harus digunakan dengan sangat hati-hati pada pasien dengan stenosis aorta dan hipertensi pulmonal.

2. Diuretik Loop diuretik telah dianggap sebagai landasan pengobatan CPE selama bertahun-tahun. Furosemide paling sering digunakan. Loop diuretik dianggap menurunkan preload melalui 2 mekanisme: diuresis dan vasoaktivitas langsung (venodilatasi).

3. Morfin sulfat

Penggunaan morfin sulfat dalam CPE untuk reduksi preload telah menjadi hal biasa selama bertahun-tahun, tetapi bukti yang baik yang mendukung efek hemodinamik yang menguntungkan masih kurang. Data menunjukkan bahwa morfin sulfat dapat berkontribusi pada penurunan curah jantung dan mungkin terkait dengan peningkatan kebutuhan untuk masuk ICU dan intubasi endotrakeal.

Secara umum, intubasi endotrakeal dan ventilasi mekanis digunakan ketika pasien dengan CPE tetap hipoksia meskipun oksigenasi tambahan noninvasif maksimal, ketika pasien memiliki bukti kegagalan 
pernapasan yang akan datang (misalnya, lesu, kelelahan, diaphoresis, kecemasan yang memburuk), atau ketika pasien secara hemodinamik tidak stabil (hipotensi, takikardik berat). Ventilasi mekanis memaksimalkan pengiriman oksigen dan ventilasi miokard. Tekanan ekspirasi akhir positif (PEEP) umumnya direkomendasikan untuk meningkatkan patensi alveolar dan untuk meningkatkan pengiriman oksigen dan pertukaran karbon dioksida [8].

Ventilasi mekanis bekerja dengan menerapkan tekanan napas positif dan bergantung pada kepatuhan dan ketahanan sistem saluran napas, yang dipengaruhi oleh seberapa besar tekanan yang harus dihasilkan oleh ventilator untuk memberikan volume tidal (TV) tertentu. TV adalah volume udara yang masuk ke paru-paru selama inspirasi [8].

Saat menempatkan pasien pada ventilasi mekanis, terjadi perubahan pada ventilasi tekanan negatif alami menjadi ventilasi tekanan positif. Hal ini akan mempengaruhi fisiologi jantung-paru dan dapat mengubah status hemodinamik pasien. Penambahan ventilasi tekanan positif meningkatkan tekanan interthoraks. Peningkatan tekanan interthoraks akan menyebabkan penurunan preload ventrikel kanan, serta preload dan afterload ventrikel kiri. Ini juga akan meningkatkan afterload ventrikel kanan [6]. Meskipun efek ini dapat memiliki perubahan minimal pada hemodinamik orang yang sehat, efek ini dapat menyebabkan perubahan yang besar pada hemodinamik pasien yang sakit kritis. Misalnya, pasien dengan edema paru akut akan mendapat manfaat dari preload yang berkurang sementara seseorang yang mengalami syok septik tidak [8].

Setelah keputusan dibuat untuk menempatkan pasien pada ventilasi mekanis, dokter dapat memberikan beberapa pilihan berbeda tentang cara memasang ventilator. Ada banyak jenis mode ventilasi, seperti assist control (AC), volume control (VC) Intermittent mandatory ventilation (IMV), Synchronized intermittent mandatory ventilation (SIMV), dan Pressure Support Ventilator (PSV). Ventilator kemudian dapat disetel untuk memberikan volume atau tekanan tertentu. Beberapa suara terkemuka dalam pengobatan darurat dan perawatan kritis merekomendasikan penggunaan volume control (VC) karena mudah digunakan, aman, dan tersedia di semua ventilator. Selanjutnya, ini memberikan dukungan ventilator lengkap yang mengimbangi kelelahan pada pasien yang sakit kritis [9].

Setelah memilih mode, parameter lainnya harus diatur pada ventilator. Parameter tersebut adalah laju pernapasan (RR), laju aliran inspirasi (IFR), fraksi oksigen inspirasi $\left(\mathrm{FIO}_{2}\right)$, dan tekanan ekspirasi akhir positif (PEEP). Laju pernapasan umumnya disesuaikan untuk bergerak menuju normokapnia, atau untuk mengimbangi asidosis berat. Laju aliran inspirasi adalah seberapa cepat inspirasi diberikan, umumnya dinyatakan dalam liter/menit. $\mathrm{FIO}_{2}$ adalah fraksi udara inspirasi dan harus diatur ke tingkat terendah untuk mencapai $\mathrm{SpO}_{2}$ 92$96 \%$, karena hiperoksemia telah terbukti meningkatkan mortalitas pada pasien yang sakit kritis. PEEP digunakan untuk meningkatkan kapasitas sisa fungsional, dan untuk membuka alveoli yang dapat dilipat sehingga mengurangi trauma atelektatis [10].

Sebelum memulai ventilasi mekanis, seseorang juga harus mempertimbangkan obat apa yang harus disediakan untuk pengendalian nyeri dan sedasi pasca intubasi. Strategi sedasi "analgesia pertama" direkomendasikan dengan agen yang paling umum digunakan adalah fentanil karena sifat hemodinamiknya yang menyebabkan hipotensi minimal. Jika pasien masih gelisah saat mendapatkan rejimen sedasi analgesia maka agen tambahan, seperti propofol dapat ditambahkan tergantung pada hemodinamik pasien dan kebutuhan klinis [8].

Weaning ventilator adalah tindakan yang mencakup pemutusan ventilator dan pelepasan jalan nafas buatan sehingga dapat melatih pernapasan mandiri pasien. Adapun indikasi weaning yaitu penyakit dasar telah diobati dan membaik, fungsi respirasi (RR $<35 \mathrm{x}$, menit, $\mathrm{SpO}_{2}>90 \%$, PEEP $<10 \mathrm{cmH}_{2} \mathrm{O}$, volume tidal $>5 \mathrm{ml} / \mathrm{kg}$ ), kardiovaskular stabil (HR <140x/menit, bebas dari obat-obatan 
vasopressor), suhu tubuh normal, pasien sadar, cairan dan elektrolit cukup.

\section{KESIMPULAN}

Tatalaksana gagal napas merupakan tindakan cepat, tepat dan akurat serta cermat, dengan melihat kondisi klinis pasien. Pemantauan dan observasi yang ketat dapat menilai progresivitas kondisi pasien. Oksigenasi dan mode ventilator serta terapi yang tepat untuk pasien dapat mengembalikan kondisi pasien yang kritis.

\section{DAFTAR PUSTAKA}

[1] Shebl, Eman and Burns, Bracken.Respiratory Failure. NCBI. 2020

[2] Hanif et al. Laporan Kasus Perawatan Gagal Napas Akut Akibat Pneumonitis Lupus di Unit Perawatan Intensif dengan Fasilitas Terbatas. Vol.7 No. 1. 2020.

[3] Brown, Ben Creagh. Respiratory Failure. Elsevier Medicine 44:6. 2016.

[4] Dobbe, Logan MD et al. Cardiogenic Pulmonary Edema. The American Journal of the Medical Sciences. 2019
[5] Sovari,Ali A, MD, FACP, FACC. Cardiogenic Pulmonary Edema. Medscape. 2020.

[6] Pham T, Brochard LJ, Slutsky AS. Mechanical Ventilation: Canggih. Mayo Clin Proc.; 92 (9): 1382-1400. 2017.

[7] Grübler MR, Wigger O, Berger D, Blöchlinger S. Basic concepts of heartlung interactions during mechanical ventilation. Swiss Med Wkly;147:w14491. . 2017.

[8] Hickey, Sean M and Giwa, Al O. Mechanical Ventilation. NCBI. 2020.

[9] Wang L, Li X, Yang Z, Tang X, Yuan Q, Deng L, Sun X. Semi-recumbent position versus supine position for the prevention of ventilator-associated pneumonia in adults requiring mechanical ventilation. Cochrane Database Syst Rev. 08;(1):CD009946.2016.

[10] Girardis M, Busani S, Damiani E, Donati A, Rinaldi L, Marudi A, Morelli A, Antonelli M, Singer M. Effect of Conservative vs Conventional Oxygen Therapy on Mortality Among Patients in an Intensive Care Unit: The Oxygen-ICU Randomized Clinical Trial. JAMA. 18;316(15):1583-1589.2016. 